\title{
NUCLEAR SEGREGATION AND THE DELAYED APPEARANCE OF INDUCED MUTANTS IN ESCHERICHIA COLI
}

\section{EVELYN M. WITKIN}

\section{Department of Genetics, Carnegie Institution of Washington, Cold Spring Harbor, New York}

The existence of a cytologically demonstrable nucleus in the bacterial cell is no longer seriously in question. There is, however, no direct evidence that the Feulgen-positive staining bodies generally considered to represent the nuclear or chromosomic elements of the bacterium are actually carriers of genetic material. The chromosome theory of heredity has yet to be established for bacteria.

Current acceptance of the bacterial nucleus as a cytological entity stems largely from the work of investigators who demonstrated bodies having typically nuclear reactions to stains and enzymes (Stille, 1937; Piekarski, 1940; Robinow, 1945; Tulasne and Vendrely, 1947, among others). Although there is no general agreement among bacterial cytologists as to the finer organization and structure of the nuclear body, and as to its pattern of division (see Delaporte, 1950; Bisset, 1950; Knaysi, 1951), the observation that serves as the starting point of this investigation is, I believe, sufficiently conservative to find general acceptance: namely, that the number of visibly distinct nuclear bodies (or chromosomes, or nuclear elements) is larger in logarithmically dividing cells of Escherichia coli than in resting cells. According to Knaysi (1951): "During the period of active growth (of rod-like bacteria) the rate of growth may be several times larger than the rate of reproduction. Since the rate of nuclear division is proportional to the rate of growth and, apparently, independent of the rate of reproduction, the large cells of the period of active growth are always multinuclear.... In general, however, the number of nuclei per cell undergoes reduction with the decrease in the ratio of rate of growth to rate of reproduction. In Escherichia coli, the truly resting cell is found to be uninuclear." Thus, it is possible to obtain populations of the same strain of $E$. coli having different numbers of nuclei per cell simply by selecting cultures of varying age. If a population of largely uninucleate cells is treated with a mutagenic

\footnotetext{
${ }^{1}$ This study was conducted in part under a grant from the American Cancer Society, through the Committee on Growth of the National Research Council.
}

agent such as ultraviolet radiation, colonies derived from cells in which a mutation has been induced in the single nucleus should exhibit the mutant character homogeneously, since all members of the clone would derive their nuclei from the original mutated one. If a mutation is induced in one of several nuclei in a multinucleate cell, on the other hand, segregation during the growth of the colony derived from such a heterocaryotic cell should lead to the formation of a mixed clone, containing individuals exhibiting the mutant character and individuals of the wild type. Thus, a positive correlation between the nuclear number per cell at the time of irradiation and the frequency of mixed clones after colony formation would afford presumptive evidence that the character in question has its material base in the nucleus.

The detection of colonies containing cells of two distinct genetic types requires a phenotype readily distinguishable from the wild type without the use of a selective procedure that would eliminate the normal component of a mixed colony. Fermentation characters, which can be translated into color variants on suitable media, are in this category. $\mathrm{On}$ an indicator medium such as Levene's Eosin-Methylene Blue, lactose-fermenting strains of $E$. coli give dark red colonies, and non-fermenting variants are easily detected by inspection as white colonies. When a lactosepositive strain is irradiated with ultraviolet before plating on EMB, some of the induced lactosenegative mutants obtained are found as white sectors in otherwise red colonies. Lederberg (1949) has suggested that such sectored colonies afford direct evidence of a nuclear segregation process.

Part $I$ of this investigation is a study of the correlation between the ratio of uninucleate to multinucleate cells in various populations of $E$. coli and the yield of unsectored versus sectored lactose-negative variants induced by treatment with ultraviolet radiation.

Nuclear segregation has been discussed as a possible explanation of the so-called "delayed effect," the phenomenon whereby most mutations induced in bacterial cells by radiation and chemicals are found not to be detectable until the 